4). In TCZ group, CRP and ESR were significantly lower than the other groups, although other clinical indicators were comparable (Table).

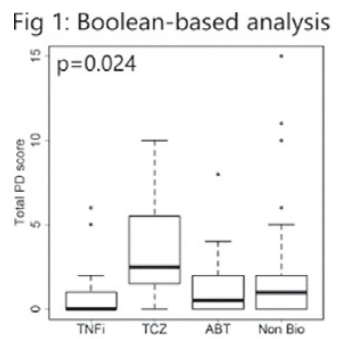

Fig 3: DAS28-ESR-based analysis

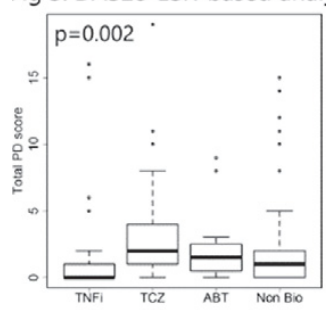

Fig 2: SDAI-based analysis

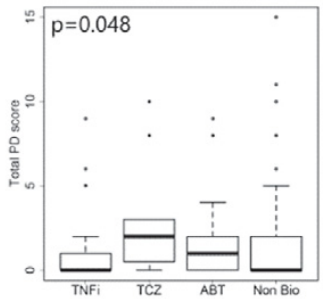

Fig 4: CDAl-based analysis

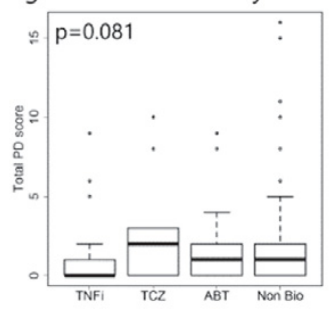

Kruskal-Wallis rank sum test
Conclusions: US revealed that CR in TCZ-using can be overestimated by BL-based, SDAl-based, and DAS28-ESR-based CR criteria. For TCZ users, CDAl-based CR criteria is more reliable than the other criteria.

Disclosure of Interest: None declared

DOI: 10.1136/annrheumdis-2017-eular.1705

\section{FRI0674 USING HIGHER IMAGE RESOLUTION OF MAGNETIC RESONANCE IMAGING OF THE CERVICAL SPINE IDENTIFIES MORE INFLAMMATORY AND STRUCTURAL LESIONS IN PATIENTS WITH AXIAL SPONDYLOARTHRITIS}

S. Krabbe ${ }^{1}$, M. Østergaard ${ }^{1}$, J. Møller ${ }^{2}$, I.J. Sørensen ${ }^{1}$, B. Jensen ${ }^{1}$, O.R. Madsen 1 , S.J. Pedersen ${ }^{1} .{ }^{1}$ Center for Rheumatology and Spine Diseases, Rigshospitalet, Copenhagen; ${ }^{2}$ Department of Radiology, Herlev Hospital, Herlev, Denmark

Background: The vertebrae of the cervical spine are rather small and it may be difficult to assess if small areas with signal intensity changes represent the bones, joints or entheses, or derive from the surrounding blood vessels.

Objectives: To investigate if image resolution affects the assessment of inflammatory and structural lesions of the cervical spine.

Methods: Forty-nine patients with axial spondyloarthritis according to the ASAS criteria started anti-TNF treatment and had "standard" resolution (std-res) and "high" resolution (high-res) MRI sequences of the cervical spine performed at baseline and after 48 weeks. 3 patients had follow-up scan already after 6-24 weeks due to study exclusion.

Std-res: STIR sequence: Voxel size $5.0 \mathrm{~mm}^{3}$ (slice thickness 4.0, spatial resolution 1x1.25); T1W sequence: voxel size $4.5 \mathrm{~mm}^{3}$ (slice thickness 4.0, spatial resolution $0.9 \times 1.25)$.

High-res: STIR sequence: Voxel size $3.1 \mathrm{~mm}^{3}$ (slice thickness 3.5 , spatial resolution 0.8x1.11); T1W sequence: voxel size $1.4 \mathrm{~mm}^{3}$ (slice thickness 3.0 , spatial resolution $0.6 \times 0.76$ ).

Images were assessed in known chronology by an experienced axSpA MRI reader (SJP) blinded to clinical data. High-res and std-res were read in random order. MRI lesions of inflammation, fat and new bone formation were defined according to the Canada-Denmark working group [1,2]. Erosions were not assessed.

Results: Inflammatory lesions: In 9 of 43 patients (21\%), inflammatory lesions were detected in the cervical spine at baseline at std-res, while this was detected in 14 of 43 patients (33\%) at high-res. Using high-res, as compared to std-res, 6 patients were reclassified from negative to positive for inflammation, 1 patient was reclassified from positive to negative, and $8 / 28$ patients remained classified as positive/negative, $\mathrm{p}=0.13$ by Exact McNemar test. The mean inflammation score was significantly higher at high-res compared to std-res (1.7 (SD 4.5) vs. 0.8 (SD 2.7), $p=0.04$ by paired t-test).

Fat lesions: 11 of 43 patients $(26 \%)$ had fat lesions in the cervical spine at baseline using std-res, while 10 of 43 patients $(23 \%)$ had this using high-res. The mean fat score was significantly higher at high-res compared with std-res (1.6 (SD 3.5) vs. 0.8 (SD 1.8), $\mathrm{p}=0.02$ by paired t-test).

Bone spurs/ankylosis: 11 of 43 patients $(26 \%)$ had bone spurs/ankylosis of the cervical spine at baseline at std-res, while 10 of 43 patients $(23 \%)$ using high-res. The mean new bone formation score was significantly higher at high-res compared with std-res (2.7 (SD 6.1) vs. 1.4 (SD 3.5), $\mathrm{p}=0.01$ by paired t-test).

Responsiveness: Standardized response mean for inflammation score at std-res was 0.15 , and at high-res 0.14 . Structural lesions remained largely unchanged in all patients.
Conclusions: More patients were classified as having inflammatory lesions in the cervical spine when using high-res MRI, compared to std-res. Likewise, mean scores of inflammatory lesions, fatty lesions and new bone formation were significantly higher compared with std-res. Further studies are needed to investigate the clinical significance of these findings as well as the frequency of these minor lesions in healthy controls.

ClinicalTrials.gov: NCT01029847.

References:

[1] Lambert RGW, et al. J Rheumatol 2009;S84:3-17.

[2] Østergaard M, et al. J Rheumatol 2009;S84:18-34.

Disclosure of Interest: None declared

DOI: 10.1136/annrheumdis-2017-eular.3200

\section{FRI0675 OBTAINING SYNOVIAL BIOPSIES FROM THE WRIST IN PATIENTS WITH NEWLY DIAGNOSED UNTREATED AND LONGSTANDING RHEUMATOID ARTHRITIS FOLLOWED BY INTRAMUSCULAR GLUCOCORTICOID AND METHOTREXATE INITIATION IS SAFE AND THE GLUCOCORTICOID TREATMENT SIGNIFICANTLY REDUCES DISEASE ACTIVITY}

S.A. Just $^{1}$, C. Nielsen ${ }^{2}$, E.K. Hejbø| ${ }^{3}$, H.D. Schrøder ${ }^{3}$, I.M.J. Hansen ${ }^{4}$, T. Barington ${ }^{2}$, H.M. Lindegaard ${ }^{1}$. ${ }^{1}$ Rheumatology; ${ }^{2}$ Clinical Immunology; ${ }^{3}$ Clinical Pathology, Odense University Hospital, Odense; ${ }^{4}$ Medicine, Svendborg Hospital, Odense University Hospital, Svendborg, Denmark

Background: The minimal invasive ultrasound-guided synovial biopsy (USG-SB) method has been shown to be safe and tolerable. The method has accelerated the research field of using synovial biopsies focusing on early diagnosis, disease stratification, biomarker studies and in the future optimal treatment selection for the individual patient. Here synovial biopsies obtained from patients with early arthritis before therapy initiation are essential. A major issue in newly diagnosed RA patients but also in RA patients with longstanding active RA, is to combine an effective fast working treatment with safely obtaining synovial tissue without delaying treatment initiation. In the EULAR early arthritis recommendations, prompt treatment initiation is recommended by combining glucocorticoid bridge therapy with disease-modifying antirheumatic drugs (DMARD). It is therefore essential that accepting synovial biopsy, does not delay start of fast remissioninducing treatment. Especially if synovial biopsies by the USG-SB method in the future shall be used systematically for detailed disease stratification and personalized treatment decisions.

Objectives: Safety of using intramuscular glucocorticoid injection (IGI) immediately after the USG-SB procedure in patients with newly diagnosed untreated RA or longstanding active RA, and the effect of IGI on disease activity after 4 weeks. Methods: Wrist synovial biopsies were taken) at inclusion and after 6 months from 22 patients with newly diagnosed, untreated RA and 15 with longstanding RA (>5 years). After biopsies patients were offered an IGI of $2 \mathrm{ml}$ of methylprednisolone acetate (Depo Medrol) $40 \mathrm{mg} / \mathrm{ml}$. Early RA patients were also started on methotrexate. Disease activity scores in 28 joints (DAS28) were recorded at day of biopsy and again after 4 weeks. Safety data were obtained after 5 days (telephone), 2 weeks (questionnaire) and at first clinical evaluation (4 weeks) after biopsy. Patient-reported outcomes (PRO) with pain, swelling and stiffness of biopsied joint were obtained at day of biopsy and after two weeks.

Results: At present time, all patients have undergone first biopsy and $18 / 37$ second biopsy. At the EULAR congress complete data will be presented. $68 \%$ of all patients accepted IGI after first biopsy currently 39\% after second procedure. Patients accepting IGI after first biopsy did not have higher DAS-28 (early RA group $(p=0.15)$, longstanding $R A(p=0.06))$. Time to first follow-up was not significantly different for patients accepting IGI (early RA group $(p=0.17$ ), longstanding RA $(p=0.05))$. Two weeks after biopsy, PRO was not significantly different when comparing IGI vs non-IGI treated. For all patients, DAS-28 was significantly reduced in the group receiving IGI at first clinical evaluation after synovial biopsy ( $p=0.004$, without IGI $\triangle$ DAS28: -0.5 , with IGI $\triangle$ DAS28: -1.7 ). Conclusions: Start of treatment with IGI combined with DMARD after obtaining synovial biopsies by the USG-SB procedure from patients with early untreated $\mathrm{RA}$ and longstanding RA is safe, and reduces disease activity more than without IGI.

Disclosure of Interest: None declared

DOI: 10.1136/annrheumdis-2017-eular.2491

\section{FRI0676 A PROPOSAL FOR A SIMPLE ULTRASOUND METHOD FOR} THE DIAGNOSIS OF EARLY RHEUMATOID ARTHRITIS

T. Serban ${ }^{1,2}$, I. Satulu $^{3}$, O. Vutcanu ${ }^{1}$, M. Milicescu ${ }^{1,2}$, C.M. Mihai ${ }^{1,2}$ M. Bojinca ${ }^{1,2} .{ }^{1}$ Internal Medicine and Rheumatology, "Dr. I. Cantacuzino" Clinical Hospital; ${ }^{2}$ Internal Medicine and Rheumatology, "Carol Davila" University of Medicine and Pharmacy, Bucharest, Romania; ${ }^{3}$ Rheumatology, Kalmar County Hospital, Kalmar, Sweden

Background: At this point, the classification criteria for rheumatoid arthritis (RA) are well known and generally applied in clinical practice. (1) Ultrasound (US assessment can help in distinguishing the patients with early RA (ERA) within the patients with early inflammatory arthritis (EIA).

Objectives: The aim of this study was to develop an US method for the diagnosis 